\title{
OCUPAÇÃO NA ZONA COSTEIRA DO SUL DE SANTA CATARINA: UMA ANÁLISE HISTÓRICA DE VETORES E PROCESSOS
}

\author{
Daniel Cohenca ${ }^{1}$ \\ Marinez E. G. Scherer ${ }^{2}$ \\ Carlos A. O. Vieira ${ }^{3}$
}

\begin{abstract}
Resumo: Considerando a ocupação e uso do solo como processos que seguem padrões vinculados ao contexto histórico e às características naturais e humanas de uma região, este trabalho, a partir de entrevistas, observações de campo e construção de SIG, identifica os vetores de mudança e compreende a dinâmica de ocupação em dois municípios da zona costeira sul do Estado de Santa Catarina. Os padrões de uso encontrados foram classificados e mapeados. $\mathrm{Na}$ área rural, o acesso, a subdivisão de propriedades da agricultura familiar e o aumento de áreas para uso rural são os principais vetores de mudanças. Na porção próxima a orla a implantação da infraestrutura nos loteamentos, que ocupam a faixa de costa, com 60 mil lotes registrados, foi o fator detectado que mais influência teve nas mudanças de uso e cobertura da terra. Nas sedes urbanas, as várias trajetórias na história de ocupação geraram diferenças na sua atual formação populacional e nos vetores do recente crescimento urbano.
\end{abstract}

Palavras-chave: Ocupação costeira; Litoral; Santa Catarina; Passo de Torres; Balneário Gaivota

\section{SANTA CATARINA SOUTHERN COAST OCCUPATION: A HISTORICAL ANALYSIS OF DRIVERS AND PROCESSES}

\begin{abstract}
Considering the occupation and land use as processes that follow patterns related to the historical context and the natural and human characteristics of a region, the objective of this work was to identify drivers of change, as well as, understand the dynamics of occupation in two municipalities from southern coastal areas of Santa Catarina state, Brazil, using multiple geography techniques. Different patterns were identified, classified and mapped. In rural areas, access, subdivision property of small farms and increase areas for agriculture and cattle are the main drivers of change. At the shore portion of the municipalities, infrastructure deployment in the coastal settlements, which occupy almost all of the $32 \mathrm{~km}$ of coastline with 60,000 plots of land registered, was detected as the most important factor that influence on use and cover change. At the urban centers, the differences in occupation history generated differences in current population formation and in the drivers that are responsible for the urban growth.
\end{abstract}

Keywords: Coastal Occupation; Land Use and Land Cover Change; Santa Catarina; Passo de Torres; Balneário Gaivota

\footnotetext{
1 Inst. Brasileiro de Meio Ambiente e Rec. Naturais Renováveis - IBAMA dcohenca1@gmail.com, Rua Conselheiro Mafra, 784, Florianópolis/SC.

${ }^{2}$ Depto de Geografia, Centro de Filosofia e Ciências Humanas, Universidade Federal de Santa Catarina $\mathrm{CFH} / \mathrm{UFSC}$.

${ }^{3}$ Depto de Geografia, Centro de Filosofia e Ciências Humanas, Universidade Federal de Santa Catarina $\mathrm{CFH} / \mathrm{UFSC}$.
} 


\section{OCUPACIÓN EN LA ZONA COSTERA DEL SUR DE SANTA CATARINA: UN ANÁLISIS HISTÓRICO DE VECTORES Y PROCESOS}

Resumen: Considerando la ocupación y uso del suelo como procesos que siguen patrones vinculados al contexto histórico y a las características naturales y humanas de una región, este trabajo, a partir de entrevistas, observaciones de campo y construcción de un sistema de información geografica, identifica los vectores de cambio y comprende la dinámica de ocupación en dos municipios de la zona costera sur del Estado de Santa Catarina, Brazil. Los patrones de uso encontrados fueron clasificados y asignados. En el área rural, el acceso, la subdivisión de propiedades de la agricultura familiar y el aumento de áreas para uso rural son los principales vectores de cambios. En la porción próxima a la implantación de la infraestructura en las parcelas, que ocupan la franja de costa, con 60 mil lotes registrados, fue el factor detectado que más influencia tuvo en los cambios de uso y cobertura de la tierra. En las sedes urbanas, las diversas trayectorias en la historia de ocupación generaron diferencias en su actual formación poblacional y en los vectores del reciente crecimiento urbano.

Palabras clave: Ocupación costera; Litoral; Santa Catarina; Passo de Torres; Balneario Gaviota

\section{INTRODUÇÃO}

A conformação do espaço geográfico é resultado da organização da sociedade em um processo híbrido de ideias e ações num certo tempo (SANTOS, 2006). Portanto, espaço e tempo são fundamentais para compreender a mudança dos fenômenos, sendo ampla a aplicação e grande a demanda por estudos nessas escalas, já que, no planejamento, espaço e tempo são necessários à compreensão da dinâmica socioespacial e ambiental (BESER DE DEUS, 2013). Da mesma forma, a adequada identificação dos vetores de mudança que determinaram a conformação geográfica de uma região ao longo do tempo é crucial em investigações de mudança de uso e cobertura do solo, ou como ferramenta de suporte ao planejamento territorial (VERBURG et al., 2004; VERBURG, 2014).

O litoral foi a primeira porção do Brasil ocupada pelos colonizadores, no entanto a intensidade, modelo e dinâmica espacial de ocupação dos diferentes trechos do litoral brasileiro dependeram de conjunturas naturais, geográficas, econômicas e de políticas públicas, que variaram muito no espaço e ao longo do tempo (MORAES, 2007).

$\mathrm{Na}$ atualidade o litoral brasileiro segue em acelerada ocupação com rápido adensamento populacional em localidades até então isoladas e ambientalmente preservadas. Como consequência, vários ambientes litorâneos foram degradados pela poluição e exploração desordenada de recursos naturais (DIEGUES, 1999). Os principais desafios para minimização dessa tendência estão relacionados ao planejamento do uso do espaço costeiro e marinho, 
especialmente regulando e monitorando as atividades econômicas industriais, portuárias, de veraneio e turismo, de exploração de recursos naturais e de desenvolvimento urbano (ASMUS; KITZMANN; LAYDNER, 2004; MMA, 2002; MORAES, 2007).

Em Santa Catarina, originalmente, os municípios do litoral sul eram recobertos por restingas formadas sobre campos eólicos de dunas móveis e fixas, banhados e lagoas costeiras (CORDAZZO; SEELIGER, 1995). Embora sejam em grande parte áreas de preservação permanente pela legislação ambiental, nas últimas décadas essas restingas vêm sendo ameaçadas pelo avanço da ocupação humana que as tem convertido aceleradamente em outros tipos de cobertura.

Diversos fatores econômicos e sociais, resultantes tanto de ações governamentais quanto da iniciativa privada incluindo expansão do mercado imobiliário, industrialização, ampliação da infraestrutura, plantio de espécies madeireiras exóticas (Pinus spp. e Eucalyptus spp.) e incentivos agrícolas direcionados entre outros, vêm, historicamente, influenciando taxas de ocupação (BASTOS, 2007; NUNES, 2008; PEREIRA, 2003). Neste contexto, a qualificação e quantificação adequadas dos vetores de mudança são os primeiros desafios na busca de alternativas que modifiquem as tendências históricas de mudanças.

Desta forma, os objetivos deste estudo foram identificar quais os principais vetores que influenciaram as mudanças de uso e cobertura da terra na zona costeira do sul de Santa Catarina, com ênfase nas últimas quatro décadas e mapear as porções dos territórios municipais com diferentes padrões de ocupação os quais influenciarão na velocidade e tendência de alteração desta paisagem no futuro.

\section{Área de estudo}

Para uma análise aprofundada dos vetores de mudança de uso e cobertura da terra no litoral sul, dois municípios, Passo de Torres e Balneário Gaivota (Figura 1) foram escolhidos já que, em função de características tais como do avanço de atividades rurais agropecuárias, urbanização, aumento no fluxo turístico e ampliação da infraestrutura de acesso e serviços, tais municípios podem ser considerados representativos do processo de ocupação. Ao mesmo tempo estes municípios ainda concentram expressivos remanescentes naturais, propiciando iniciativas de intervenções na dinâmica de ocupação com viés de conservação ambiental. 
Figura 1 - Localização dos municípios de Passo de Torres e Balneário Gaivota.

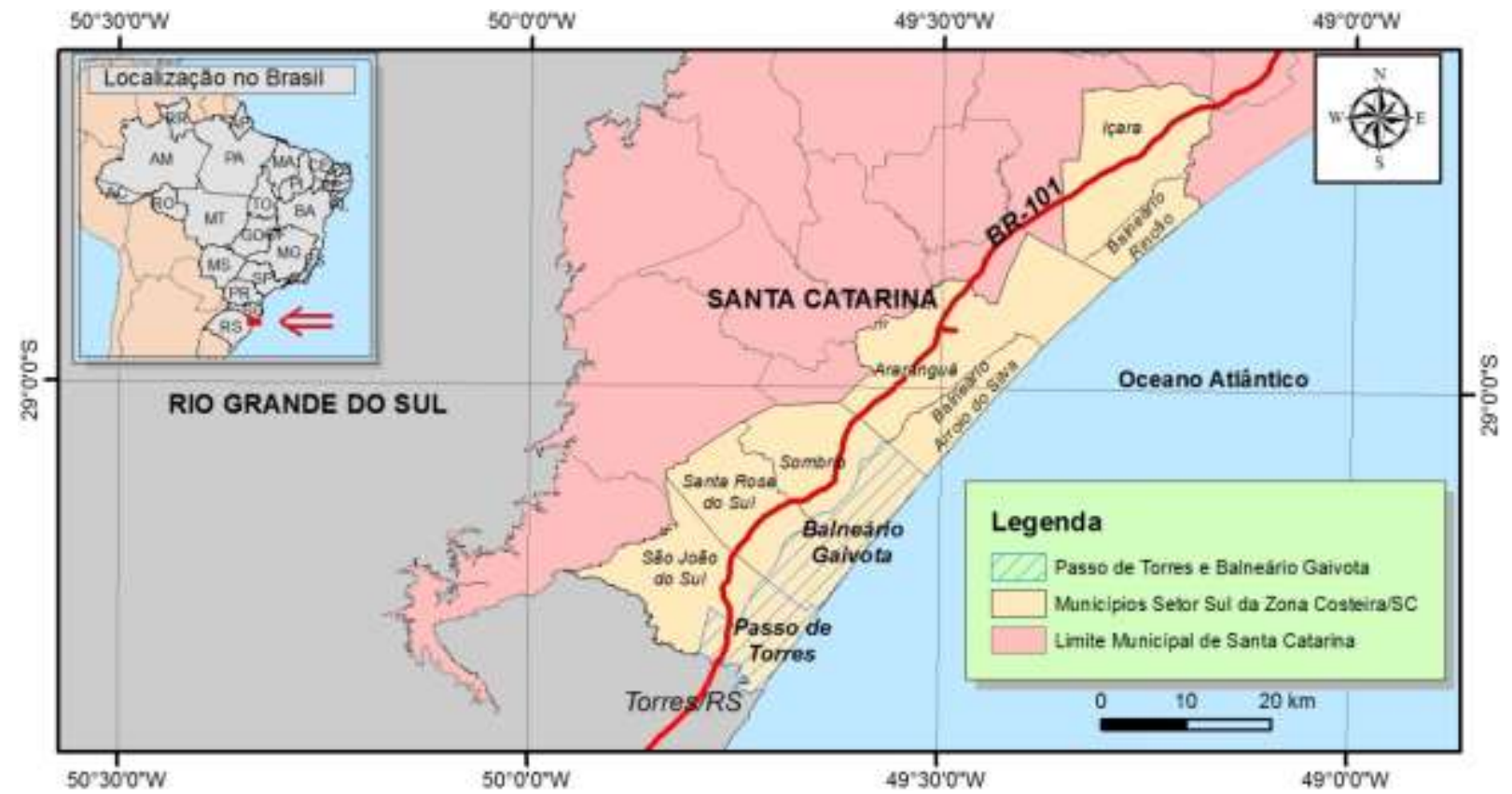

Fonte: Limites Municipais: IBGE, 2014a. (COHENCA, 2016).

Dados demográficos indicam similaridades na dinâmica populacional dos municípios e, por apresentarem características ambientais e de ocupação semelhantes também, foram tratados conjuntamente. Entre 2000 e 2010, o aumento populacional foi de $51 \%$ e o aumento no número de domicílios foi de 73\%. Em comparação, neste período o crescimento da população no Brasil foi de 12,5\% e o de domicílios 28,0\% (IBGE, 2014a; IBGE, 2014b). Estes dados denotam a intensidade de aumento populacional na área de estudo, representando um aumento no número de domicílios de quase três vezes mais do que a média nacional.

\section{Métodos}

Inicialmente foi realizada uma análise de imagens LandSat8 de 2014 já classificadas pelo método de classificação supervisionada por Máxima Verossimilhança (COHENCA; CARVALHO, 2015), sendo utilizadas também imagens do satélite RadidEye (MMA), aerofotografias de 1938 (Secretaria de Estado de Planejamento), aerofotografias de 1978 (DNPM) e aerofotografias de 1996 (Secretaria de Patrimônio da União - SPU). As imagens foram georreferenciadas em datum WGS84, os dados cartográficos de zoneamento em formato digital e os dados de estradas e loteamentos urbanos foram cedidos pelas prefeituras municipais. Os dados foram integrados em um Sistema de Informações Geográficas (SIG) que permitiu a 
espacialização prévia das entrevistas e das áreas a serem observadas em campo.

Para captar os processos motivadores de mudanças de uso da terra, a extensão temporal do estudo foi definida em 40 anos assumindo-se assim o acúmulo destes fatores no conjunto dos processos de ocupação.

As entrevistas foram realizadas com informantes-chave segundo o método de amostragem bola de neve (BERNARD, 2006; BISOL, 2012). Considerando os diversos grupos de interesse, foi feita uma adequação específica do método para identificação dos entrevistados em cada grupo (COHENCA, 2016). As entrevistas foram realizadas nas áreas rurais e urbanas, na faixa litorânea e interior, sendo os entrevistados selecionados dentre os grupos: a) representantes do poder público municipal da área de ordenamento urbano e rural, objetivando a compreensão dos rumos da política atual que influenciam o uso e ocupação do solo; b) funcionários dos cartórios locais, objetivando a compreensão do histórico da dinâmica fundiária (transações, desmembramentos e loteamentos); c) particulares detentores de conhecimento histórico das transformações da ocupação no seu ambiente microrregional rural; d) representantes de proprietários das grandes fazendas da região para compreensão da história fundiária e de uso econômico destas grandes áreas; e) loteadores e agrimensores conhecedores da história dos loteamentos litorâneos, em um total de 25 entrevistas ${ }^{4}$.

As entrevistas foram qualitativas, semiestruturadas e orientadas para a compreensão dos fluxos de ocupação rurais e urbanos e seus aspectos socioeconômicos e ambientais, objetivando o mapeamento dos principais padrões de ocupação e identificação dos seus elementos motivadores. Tal técnica busca estimular o entrevistado a desenvolver e aprofundar sua narrativa, porém reconduzindo a entrevista quando eventualmente desviada (RICHARDSON; PERES, 1985).

Além das entrevistas foram realizadas observações de campo em 42 pontos, alguns previamente definidos com base no SIG, outros escolhidos após as entrevistas, objetivando uma melhor compreensão e qualificação das informações.

\section{Resultados}

Em função de seu padrão histórico de ocupação, cinco regiões distintas foram identificadas na área de estudo:

\footnotetext{
${ }^{4}$ Aprovada no Comitê de Ética em Pesquisa com Seres Humanos da Universidade Federal de Santa Catarina - CEPSHUFSC CAAE: 44295515.1.0000.0121.
} 


\section{a. Pequenas propriedades situadas na zona rural}

Até a primeira metade do século $\mathrm{XX}$, as pequenas propriedades rurais abrangiam a faixa que vai da Lagoa do Sombrio ao mar. Só havia acesso por estradas de carro de boi. Os terrenos litorâneos, encharcados ou cobertos de dunas, tinham pouca serventia, eram de difícil acesso e, na percepção da época, muito distantes. Os campos de dunas somente serviam para a pastagem do gado que ficava solto em época de alagamento, mas foi relatado que algumas cabeças de gado atolavam nos banhados e acabavam por perecer.

O baixo valor das terras, o difícil acesso e a baixa aptidão para atividades produtivas, aliados às necessidades financeiras dos proprietários, na maioria agricultores familiares que viviam nos próprios lotes, ocasionaram a venda de parte das terras. Alguns venderam a porção litorânea dos lotes, formada apenas por dunas "onde nem pastagem vingava" a compradores do Rio Grande do Sul. Enquanto outros simplesmente não registraram em cartório essa porção para que não incorressem impostos sobre estas terras improdutivas.

Na década de 1970 uma grande empresa de produção de madeira de reflorestamento passou a adquirir os terrenos que, além de distantes das casas eram também alagáveis, com presença de dunas e de pouco uso, pagando um valor atrativo aos proprietários que possuíssem escritura. Este movimento resultou na venda de quase todas as propriedades numa faixa paralela a linha da costa.

Já a partir da segunda metade do século 20, a maioria das propriedades foram divididas por herança ou por venda de partes a vizinhos ou terceiros, mantendo apenas as terras agricultáveis em tamanho compatível a sua força de trabalho familiar. Após tantas divisões, o quadro atual se configura em predomínio de terrenos pequenos. Possuir 10 hectares nesta faixa da zona rural já é considerado um terreno grande, visto que a maioria das famílias possui áreas menores e o movimento de venda e subdivisão continua ocorrendo. Existem exceções, representadas por proprietários que ampliaram a propriedade, comprando a área de parentes, ou de vizinhos que queriam vender parte ou todo seu lote.

Característica marcante do padrão de ocupação dessa região é a presença de moradores fixos, agricultores e pescadores das lagoas do Sombrio e Caverá, produção agrícola e pecuária de pequena escala bem diversificada, havendo relatos de poucos sítios de veraneio nestas comunidades. Existe uma vida comunitária relativamente intensa e relações quase nulas com as 
grandes fazendas de gado e de reflorestamento.

A produção de arroz às margens da Lagoa do Sombrio foi extinta há alguns anos, principalmente em função do impacto do uso de agrotóxicos sobre a pesca, atividade importante aos moradores, tanto para consumo quanto para o comércio.

\section{b. Grandes propriedades situadas na zona rural}

Esta região abrange aproximadamente a metade da zona rural da área de estudo sendo composta de três fazendas de gado e uma fazenda de reflorestamento que possuem áreas com 500 a 4.000 ha, produção em escala industrial (gado ou madeira de Pinus e Eucalyptus) e proprietários não residentes.

A maior propriedade da área estudada é a fazenda Rio Novo Florestal que possui em torno de $3.800 \mathrm{ha}$, ocupando uma faixa paralela à linha de costa de aproximadamente $20 \mathrm{x} 2 \mathrm{~km}$, consolidada na década de 1970 pela compra de parte dos terrenos que, em maioria, se estendiam desde a Lagoa do Sombrio até o mar. Estes terrenos eram de dunas e banhados. Logo após a aquisição foi retirado o gado, a empresa abriu canais artificiais para drenar os banhados, tendo atualmente como uso a produção de madeira de Pinus e Eucalyptus. Presentemente persistem alguns sítios isolados em meio à contínua monocultura, pertencentes a proprietários que na época não venderam suas áreas à empresa. A empresa deixou poucos remanescentes expressivos de vegetação nativa.

Pertencem também a esse padrão de uso e ocupação, fazendas de gado de corte, na área norte de Balneário Gaivota, formadas há mais de quatro décadas. Nesta área houve a manutenção de expressiva faixa de vegetação de restinga nativa e lagoas pouco alteradas.

\section{c. Rizicultura}

A área identificada como de predomínio da rizicultura corresponde a aproximadamente 19\% do município de Passo de Torres, ao noroeste da rodovia BR101, não sendo encontrada no município de Balneário Gaivota. Há 35 anos as lavouras de arroz já existiam, mas em torno de $70 \%$ da área possuía cobertura florestal de mata paludosa alagável. Em função de ações de fiscalização há aproximadamente 20 anos, o desmatamento cessou e as áreas de plantio não foram ampliadas, mantendo-se estáveis também os limites fundiários, sem registros de novas transações fundiárias expressivas.

No início, o cultivo do arroz era realizado com enxada, hoje a produção é mecanizada. 
Nesta área estima-se que existam apenas oito propriedades (quatro moradores locais e quatro que vivem fora da propriedade em cidades próximas). Além do plantio de arroz, há pequenas chácaras, criação de gado e produção de culturas agrícolas variadas.

\section{d. Loteamentos litorâneos}

Esta região compreende terrenos situados fora da sede dos municípios, mas definidos como Zona Urbana pelos zoneamentos municipais. Originalmente composta por praias, campos de dunas, banhados e lagoas costeiras, há expressivos remanescentes da cobertura vegetal nativa de restinga herbácea e vegetação típica de banhado.

Segundo dados das prefeituras municipais, nos dois municípios, numa extensão de $32 \mathrm{~km}$ de costa, foram registrados 72 terrenos litorâneos com diversas metragens de frente para o mar e com 600 a 1500 metros de largura (sentido costa-interior). Destes, 54 foram desmembrados em loteamentos, em sua maioria loteados nas décadas de 70 e 80 , havendo hoje 59.529 lotes com até $350 \mathrm{~m}^{2}$ registrados e 18 terrenos não desmembrados. Em se tratando dos 54 loteamentos registrados, a situação de implementação e urbanização é variada: 13 atendem ao que a Lei Federal $n^{\circ} 11.977 / 2009$ define como área urbana consolidada (17\% da área); 16 estariam com implantação de arruamentos, porém ainda em estágio de ocupação incipiente, não caracterizado como consolidado ( $29 \%$ da área); 25 deles não têm arruamento ou infraestrutura mínima para a ocupação urbana, sendo considerados não implantados, e sem condições para ocupação conforme legislação de parcelamento do solo urbano (31\% da área) (Tabela 1). 
Tabela 1 - Terrenos e loteamentos litorâneos nos municípios de Passo de Torres e Balneário Gaivota.

\begin{tabular}{|c|c|c|c|c|c|c|c|c|c|c|c|c|c|c|}
\hline \multirow[t]{2}{*}{ Municipio } & \multicolumn{2}{|c|}{$\begin{array}{l}\text { Terreno } \\
\text { não } \\
\text { loteado }\end{array}$} & \multicolumn{3}{|c|}{$\begin{array}{l}\text { Loteamento sem } \\
\text { implementação }\end{array}$} & \multicolumn{3}{|c|}{$\begin{array}{l}\text { Loteamento } \\
\text { implantado mas } \\
\text { ocupação não } \\
\text { caracteriza } \\
\text { urbanização } \\
\text { consolidada }\end{array}$} & \multicolumn{3}{|c|}{$\begin{array}{c}\text { Loteamento } \\
\text { implantado ocupação } \\
\text { caracteriza } \\
\text { urbanização } \\
\text { consolidada }\end{array}$} & \multicolumn{3}{|c|}{ TOTAL } \\
\hline & $\mathrm{N}^{\mathrm{v}}$ & $\begin{array}{l}\text { Área } \\
\text { (ha) }\end{array}$ & $\mathrm{N}^{\mathrm{v}}$ & $\begin{array}{l}\text { Área } \\
\text { (ha) }\end{array}$ & Lotes & $\mathrm{N}^{0}$ & $\begin{array}{l}\text { Ärea } \\
\text { (ha) }\end{array}$ & Lotes & $\mathrm{N}^{0}$ & $\begin{array}{l}\text { Área } \\
\text { (ha) }\end{array}$ & Lotes & $\mathrm{N}^{0}$ & $\begin{array}{l}\text { Área } \\
\text { (ha) }\end{array}$ & Lotes \\
\hline $\begin{array}{l}\text { Balneário } \\
\text { Gaivota }\end{array}$ & 13 & 609 & 16 & 685 & 17.508 & 9 & 743 & 17.056 & 6 & 387 & 9.220 & 44 & 2.424 & 43.784 \\
\hline $\begin{array}{l}\text { Passo de } \\
\text { Torres }\end{array}$ & 5 & 165 & 9 & 334 & 7.464 & 7 & 221 & 4.233 & 7 & 182 & 4.048 & 28 & 902 & 15.745 \\
\hline TOTAL & 18 & $\begin{array}{c}774 \\
(23 \%)\end{array}$ & 25 & $\begin{array}{r}1.019 \\
(31 \%)\end{array}$ & 24.972 & 16 & $\begin{array}{c}964 \\
(29 \%)\end{array}$ & 21.289 & 13 & $\begin{array}{c}569 \\
(17 \%)\end{array}$ & 13.268 & 72 & 3.326 & 59.529 \\
\hline
\end{tabular}

Fonte: Prefeituras municipais de Passo de Torres e Balneário Gaivota.

Dos loteamentos litorâneos já desmembrados em registro cartorial, a maior parte não tem arruamentos ou áreas públicas previstas e não respeitam a legislação ambiental em se tratando da localização dos lotes em áreas de preservação permanentes. Nesta situação estão também os 24 loteamentos com alvarás emitidos após a vigência da Lei Federal 6.799/79, a qual regulamentou o parcelamento do solo urbano. Existem 25 loteamentos sem arruamento, e nenhum destinou $35 \%$ da área para usos públicos, áreas verdes e vias de acesso conforme previsto na legislação.

Nos loteamentos não implantados, apesar da existência de lotes mapeados, registrados no Cartório Registro de Imóveis, à venda e vendidos, a falta de infraestrutura inibiu sua ocupação. Em toda a área de estudo, os 18 terrenos não loteados e os loteamentos não implantados são as áreas onde se concentra a cobertura vegetal nativa menos alterada.

A infraestrutura de acesso e a presença de rede elétrica foram os vetores preponderantes na ocupação dos lotes, além da proximidade a outros núcleos urbanizados, num sistema de atração pela vizinhança. Por outro lado, fornecimento de água, recolhimento de lixo doméstico e rede coletora de esgotos não foram reportados como fatores que influenciaram na ocupação dos loteamentos. Há diversos loteamentos cujos lotes foram vendidos que permanecem desocupados por não existir infraestrutura mínima de acesso aos lotes (Figura 2). 


\section{COHENCA, SCHERER, VIEIRA}

Figura 2 - Exemplo de loteamento com 2.000 lotes de $288 \mathrm{~m}^{2}$, registrado em 1982, mas nunca implantado, sobreposto a uma imagem RapidEye de 2012.

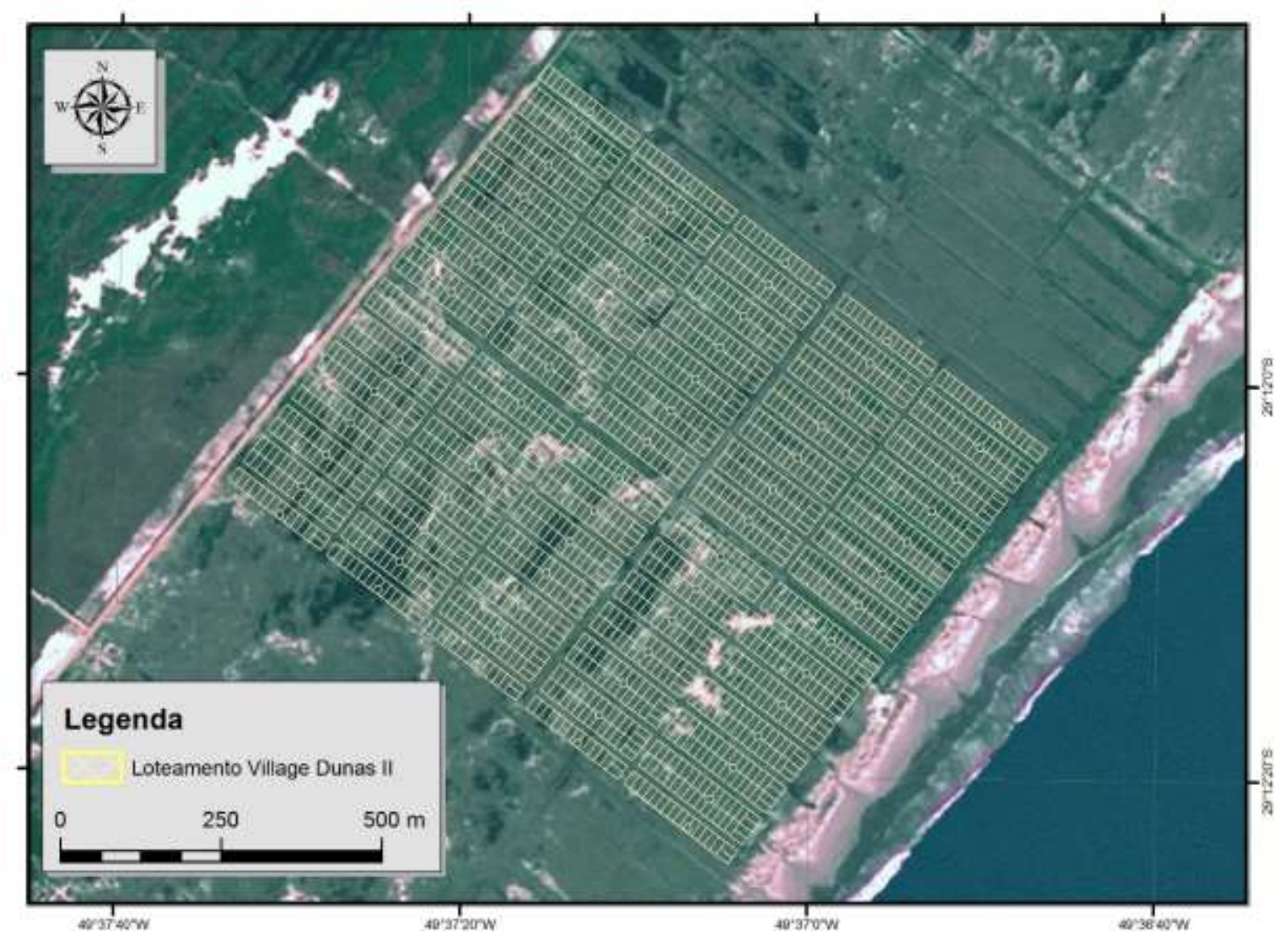

Fonte: Prefeitura Municipal de Balneário Gaivota. (COHENCA, 2016) 


\section{e. Sede urbana}

Apesar da zona urbana de ambos municípios ser formada pela sede e pela faixa de até 1500 metros em toda a extensão da orla marítima, considerou-se sede urbana municipal a porção municipal onde há a centralidade urbana em função das características diferenciadas em relação aos loteamentos litorâneos. Em Passo de Torres este padrão situa-se às margens do Rio Mampituba cuja ocupação está diretamente relacionada à passagem dos viajantes que vinham do Rio Grande do Sul a Santa Catarina em direção a Laguna. Até o final do século XIX todo o fluxo de produtos do Rio Grande do Sul para comercialização principalmente em São Paulo, era feito por essa via e, em menor escala, por Vacaria. A passagem pelo Rio Mampituba era inicialmente feita por embarcações. A partir de 1920 uma balsa passou a ser usada na travessia. Em 1964 foi feita uma ponte pênsil exclusiva para pedestres (PASSO DE TORRES, 2014).

Em 1938 havia por volta de 20 casas às margens do Rio Mampituba, mas menos de dez anos depois, em 22 de março de 1944, foi construída a capela, considerada marco inicial da cidade. A Figura 3 mostra a evolução da ocupação da sede urbana de Passo de Torres, na qual em 1978 havia pouco mais de 208 casas.

$\mathrm{Na}$ evolução histórica, três áreas de ocupações irregulares são visíveis. No bairro Passárgada cujas casas foram construídas irregularmente em áreas que secaram como consequência da construção do canal para retificação da foz do rio (uma Ação Civil Pública ${ }^{5}$ tramitando na Justiça Federal requer a demolição de todas as casas do bairro); as áreas de preservação permanente às margens do Rio Mampituba com expansão em direção a montante e construções avançando sobre as dunas ao norte da cidade (Figura 3).

Em 2008, foi construída uma ponte para veículos entre as cidades de Torres/RS e Passo de Torres/SC, a qual se tornou um dos vetores mais importantes na alteração da expansão urbana de Passo de Torres por trazer a possibilidade de cidadãos de Torres fixarem residência em Passo de Torres. Em 2012 o zoneamento urbano foi alterado, sendo aprovados edifícios de 12 pavimentos e máximo de 37 metros de altura (Figura 4). Paralelamente iniciam-se loteamentos de alto padrão tendo como público alvo os atuais moradores de Torres. 
Figura 3 - Evolução da ocupação da sede urbana de Passo de Torres. (a) Aerofotografia de 1938, destaque para a incipiente ocupação a margem do Rio Mampituba; (b) aerofotografias de 1978; (c) aerofotografias de 1996, em destaque o bairro Passárgada; (d) imagem de satélite de 2013, em destaque remanescente das dunas da sede urbana.

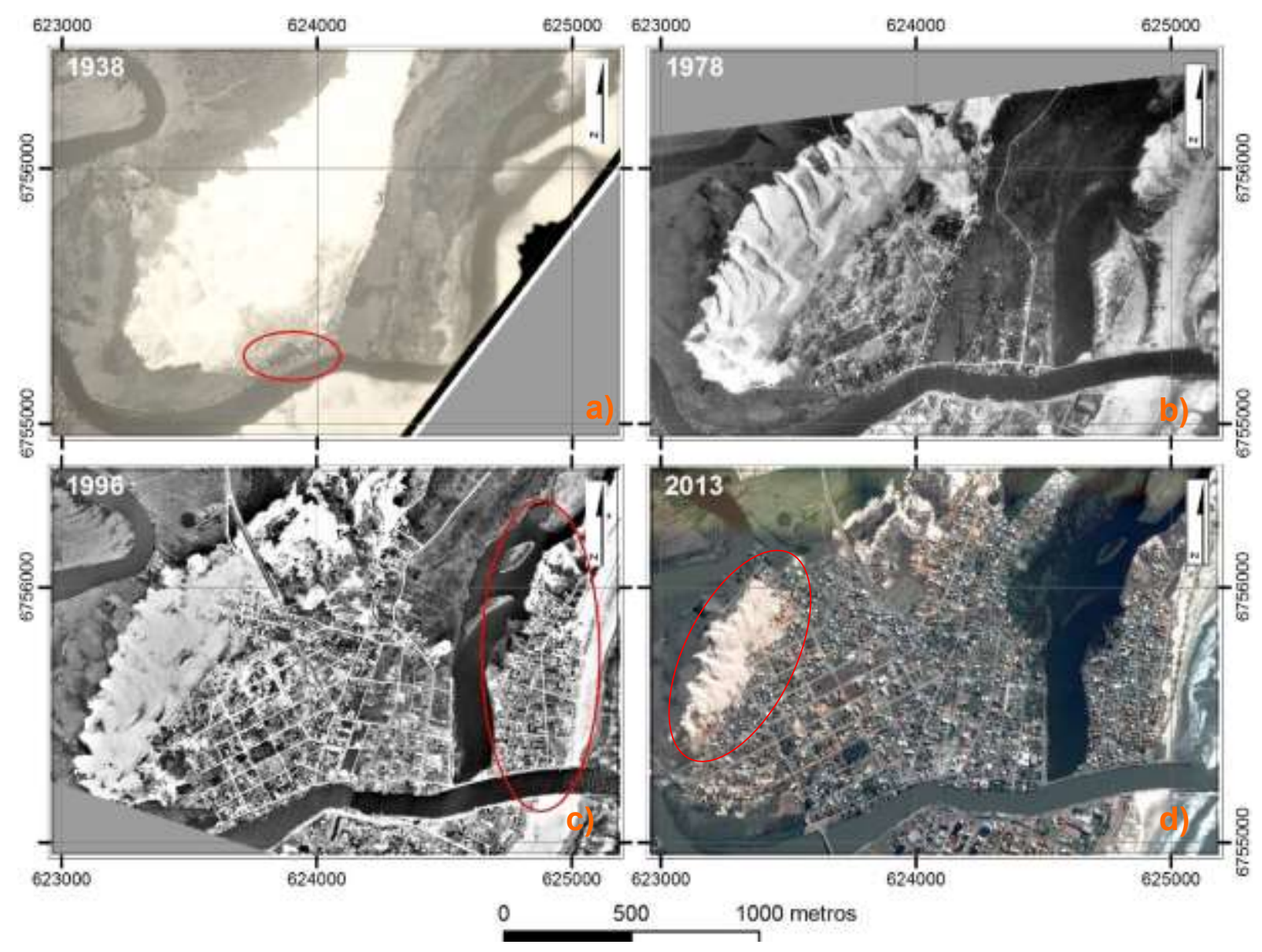

Fonte: Cohenca (2016).

Figura 4 - Ponte veicular inaugurada em 2008 e o primeiro edifício de Passo de Torres, ainda em construção (vista a partir de Torres/RS em 17/06/2014).

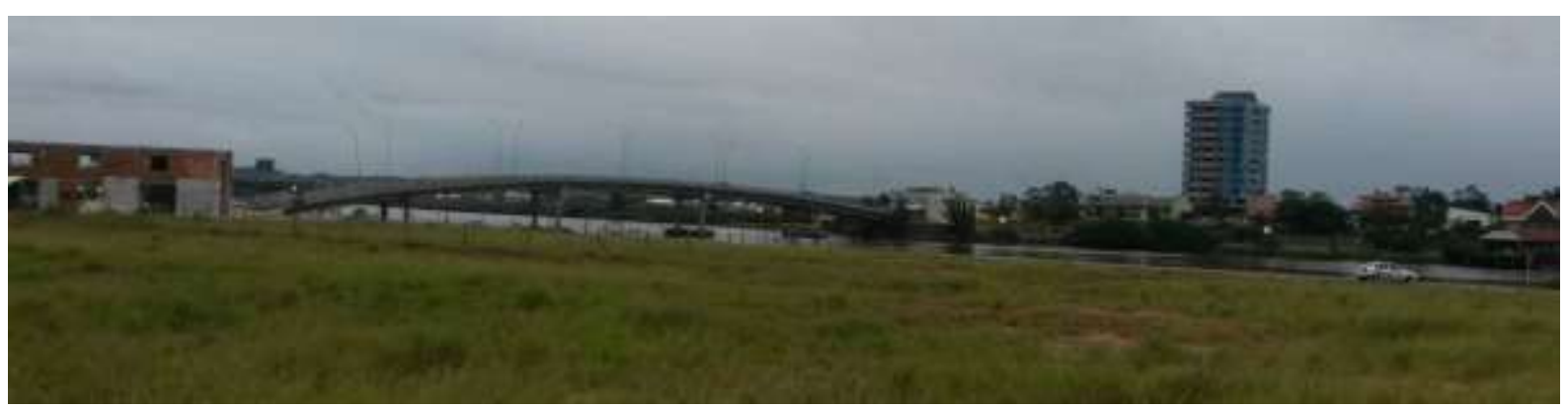

Foto: Daniel Cohenca, 2014. (COHENCA, 2016) 
Em Balneário Gaivota, a sede urbana é formada pelos loteamentos contíguos Praia Gaivota, Itapuan, Santa Rita de Cássia e Jardim Ultramar, com acesso direto proveniente da cidade de Sombrio/SC. Em 1938, existia apenas uma família na beira mar, na atual sede de Balneário Gaivota. Na aerofotografia de 1978, constata-se que naquele ano havia 371 domicílios nesta zona, sua taxa de crescimento urbano intensificou-se, resultado da emancipação do município (Figura 5).

Figura 5 - Evolução da ocupação da sede urbana de Balneário Gaivota. (a) Aerofotografia de 1938; (b) aerofotografias de 1978; (c) aerofotografias de 1996; (d) imagem de satélite de 2013.

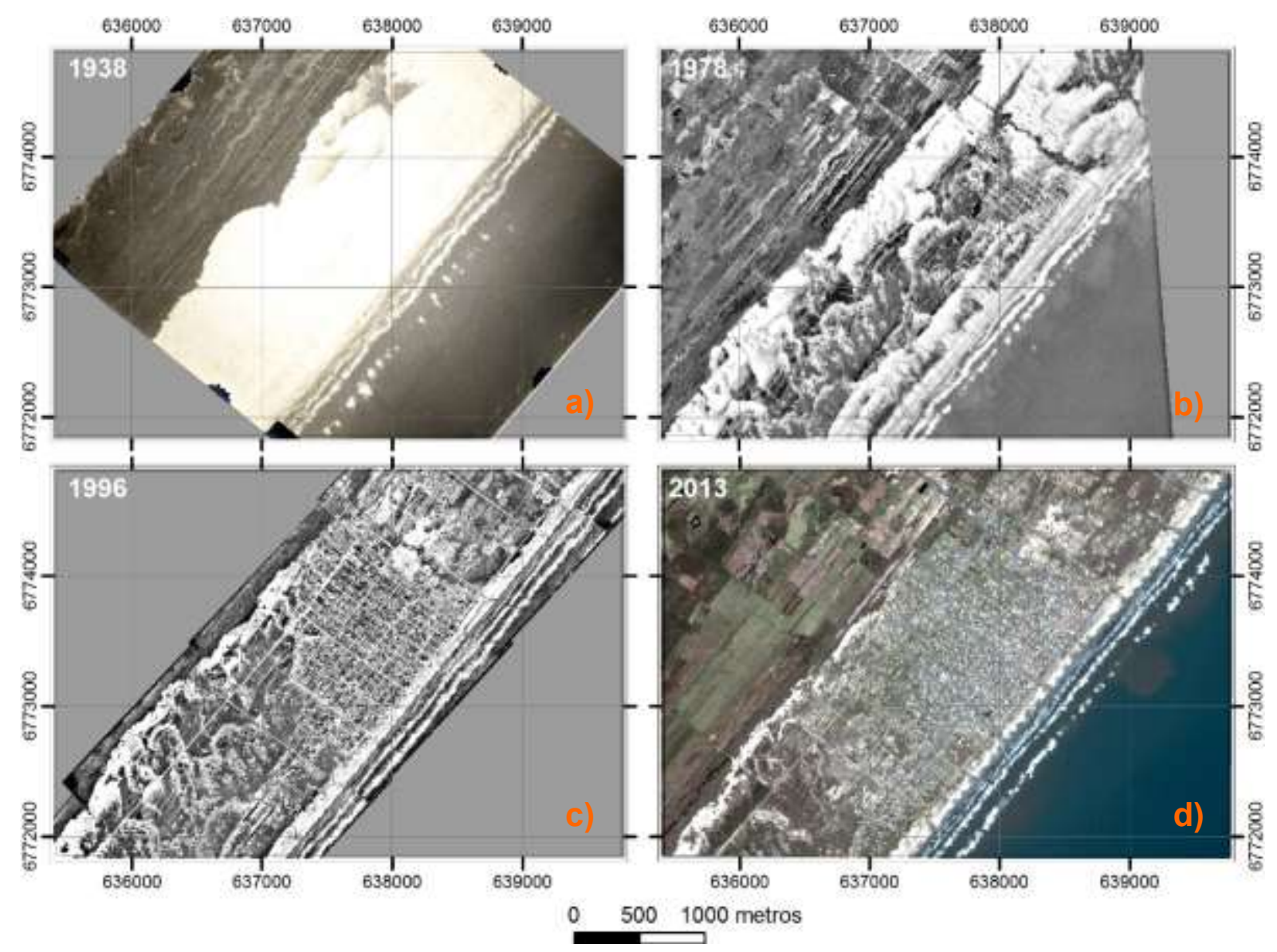

Fonte: Cohenca (2016).

Além da contínua construção de residências de veraneio, o comércio local se desenvolveu e uma migração de pessoas de baixa renda implicou na construção de casas de moradia permanente na área periférica e sobre dunas. 
O outro núcleo, fora da sede, com urbanização consolidada é o Bairro da Lagoa de Fora, situado no interior, à margem da estrada que liga Balneário Gaivota ao município de Sombrio.

\section{f. Padrões de ocupação e Uso do Solo.}

A análise integrada dos dados cartográficos de zoneamento dos municípios, classificação da imagem de satélite de 2014, entrevistas e observações em campo permitiu categorizar as áreas municipais em cinco regiões segundo características fundiárias, produtivas e de ocupação. Cada uma se mostrou homogênea no que tange ao uso atual do solo, história de ocupação, características naturais e cobertura vegetal nativa (Figura 6)

Figura 6 - Mapa dos padrões de ocupação.

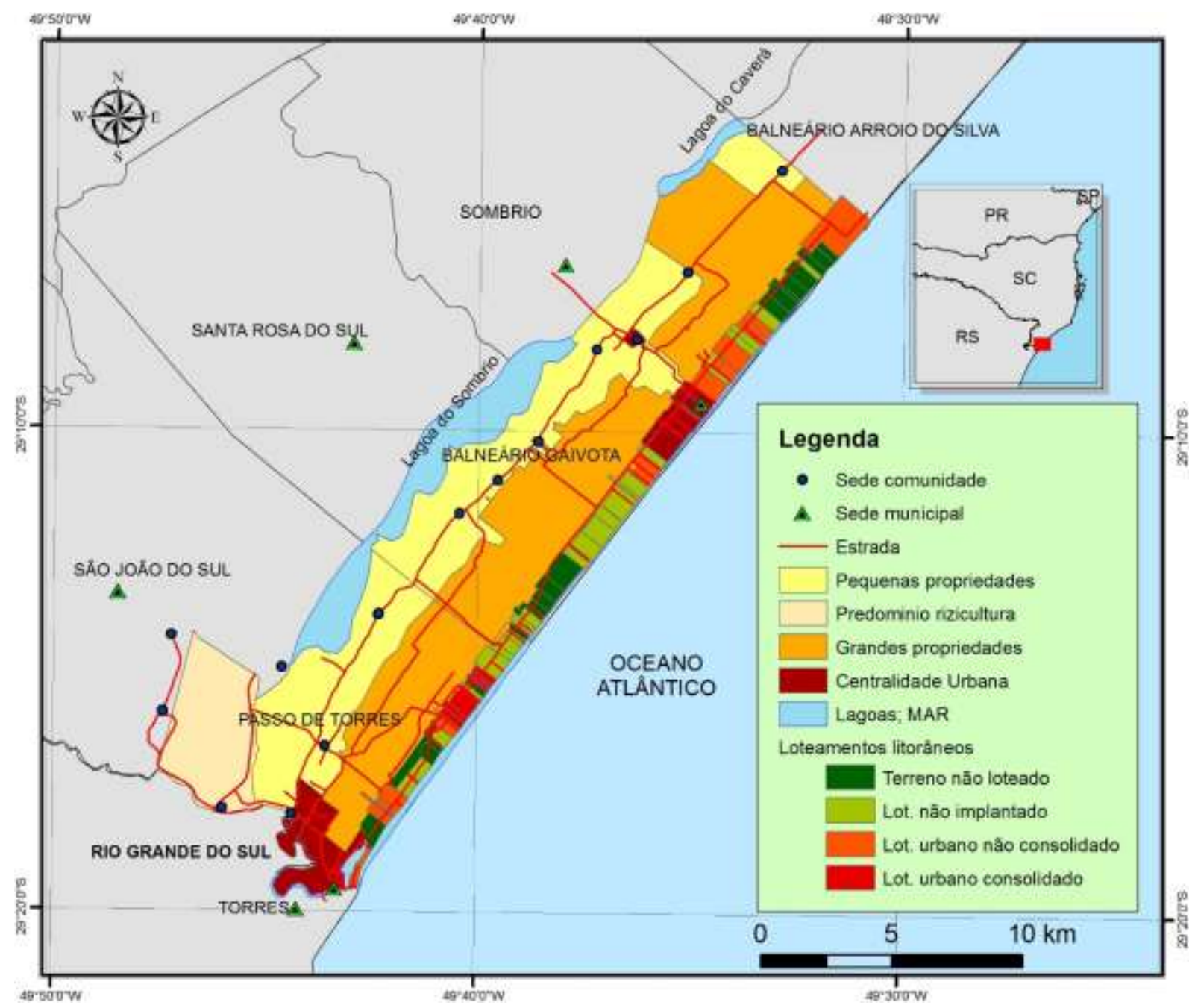

Fonte: Cohenca(2016). 
A região dos loteamentos litorâneos foi subdividida em quatro subtipos de acordo com o grau de consolidação (ocupação e implantação de infraestrutura) que se encontram: a) loteamento implantado, em estágio de urbanização consolidada; b) loteamento implantado, porém com baixa densidade populacional, casas esparsas ou concentradas em pequena porção do loteamento; c) loteamento não implantado, que foram loteados em cartório no entanto não possuem infraestrutura de arruamento e rede elétrica que favoreça sua ocupação, podem possuir algumas casas esparsas, mas ainda possui sua formação natural bem caracterizada; e d) terreno litorâneo não loteado, nos quais não ocorreu o desmembramento em lotes urbanizáveis

\section{Discussão}

Em linhas gerais, estudos sobre mudanças de uso e cobertura buscam compreender e estimar a forma como fatores físicos do ambiente, demográficos e socioeconômicos condicionam mudanças espaciais ao longo do tempo (LAMBIN et al., 2001; RINDFUSS et al., 1999; VELDKAMP; LAMBIN, 2001; VERBURG, 2014). Nesta linha, a reconstrução histórica de processos de ocupação, aliadas a ferramentas de análise espacial são úteis e necessárias (VERBURG, 2014). O uso das várias ferramentas de análise permite identificar os padrões de uso e cobertura da terra nas zonas rurais, loteamentos litorâneos e sedes urbanas, e seus respectivos vetores de ocupação.

$\mathrm{Na}$ zona rural de predomínio das pequenas propriedades, os principais vetores de mudança no uso do solo foram as vias de acesso e os desmembramentos, sendo que em alguns trechos o adensamento de pequenas chácaras chega a ser equivalente a zonas urbanas de baixa densidade. Os principais problemas ambientais identificados envolvem a expansão sucessiva de novas áreas de plantio e pastagens sobre ambientes naturais.

Já na zona rural com predomínio das grandes propriedades, as características mais marcantes da ocupação no decorrer das últimas duas décadas foram a estabilidade dos limites das propriedades e a constância das atividades ao longo do tempo. O principal vetor foi a expansão dos plantios de Pinus e Eucalyptus e de pastagens sobre áreas nativas de restinga herbácea. Essa ocupação se mostrou independente da existência de vias de acesso, já que para as necessidades agrícolas, todas as áreas podem ser consideradas atualmente bem acessíveis.

$\mathrm{Na}$ zona rural com predomínio da rizicultura, o padrão de ocupação, nas últimas três décadas, caracterizou-se pela estabilidade da estrutura fundiária e da área em uso agrícola, possivelmente como resultado da intensificação de ações de comando e controle na área. 
$\mathrm{Na}$ zona urbana de predomínio dos loteamentos litorâneos, os principais vetores que influenciam as mudanças foram a existência de registro imobiliário dos lotes, infraestrutura básica (vias de acesso, arruamento interno e rede elétrica no loteamento) e núcleos vizinhos de urbanização consolidada. Por sua vez, dentro de cada loteamento, a proximidade do mar foi o fator que mais influenciou a prioridade de novas construções.

Este padrão de ocupação acelerada, resultado de uma demanda crescente por casas de veraneio, inexistência de licenciamento ambiental, fragilidade do poder público em aplicar a legislação que protege os ambientes naturais são os fatores preponderantes para a perda dos remanescentes dos ecossistemas costeiros nativos. Recentes tentativas por aplicação das normas foram paradas nas discussões para o Zoneamento Ecológico Econômico Costeiro (SECRETARIA DE ESTADO DO PLANEJAMENTO, 2013) que evidenciaram os conflitos e incompatibilidades entre o atual padrão de ocupação e a preservação ambiental prevista na legislação ${ }^{6}$.

Com respeito às sedes urbanas, Balneário Gaivota surge como uma vila balneária e sua evolução inicial é parecida à descrita para os loteamentos litorâneos, com uma esparsa distribuição das edificações e muitos lotes vazios, mesmo na área central. Já Passo de Torres, tem uma história vinculada à sua posição estratégica à margem do Rio Mampituba, principal passagem dos tropeiros provindos do Rio Grande do Sul em direção à província de São Paulo, existindo maior concentração de domicílios permanentes na zona central. Os vetores que mais influenciaram a ocupação foram: construção de residências de veraneio, migração de pessoas de alta renda (loteamentos urbanos em Passo de Torres) e de baixa renda (periferia de Balneário Gaivotas e de Passo de Torres) e invasão de áreas de preservação permanente. O fator determinante de alocação das mudanças foi o efeito de vizinhança às atuais áreas urbanizadas.

\footnotetext{
${ }^{6}$ Recentes esforços do Governo do Estado, através da Secretaria de Estado do Planejamento, e do Ministério Público Federal buscam conciliar a ocupação nos loteamentos dos municípios do litoral sul com a conservação das áreas legalmente protegidas. Foi proposta a elaboração de termos de ajuste de conduta para cada município, onde as zonas urbanas seriam redefinidas para conter apenas as áreas urbanas consolidadas e as que possuíssem alto grau de implantação. Os demais loteamentos deveriam ser resubmetidos a licenciamento ambiental seguindo a atual legislação e os lotes que ficarem além da zona delimitada ficariam isentos de ocupação, garantindo ao proprietário transferência do direito de construir para outro lote localizados dentro do perímetro urbano instituído. (SECRETARIA DE ESTADO DO PLANEJAMENTO, 2014). A solução proposta ainda está em discussão e, segundo as entrevistas gera polêmica e ainda não foi consensuada pelas prefeituras municipais envolvidas.
} 


\section{Conclusão}

Os municípios do litoral sul de Santa Catarina possuem profundas semelhanças entre si que se iniciam pelos seus aspectos naturais de conformação geográfica da planície costeira e homogeneidade da tipologia de vegetação. Estas semelhanças se ampliam ao considerar seu histórico de ocupação e uso do solo, que no interior é mais antigo (início do século XX) e no litoral é bem mais recente (majoritariamente da segunda metade do século XX). O uso de múltiplas ferramentas do campo da geografia possibilitou cruzar informações e identificar a dinâmica temporal da construção do espaço e consequentemente a importância dos vetores de mudança ao longo do tempo. A escala de trabalho mostrou que existe uma heterogeneidade microrregional em relação aos padrões de uso e ocupação do solo.

$\mathrm{Na}$ região rural existe profunda distinção entre áreas de pequenas propriedades rurais com produção variada da agricultura familiar; áreas com algumas poucas propriedades rurais muito grandes com produção industrial de madeira e pecuária extensiva; e áreas com predominância de médias propriedades onde há predomínio de produção de arroz irrigado. Os três tipos sofreram antigo processo de antropização e restam poucas áreas de vegetação nativa.

$\mathrm{Na}$ faixa costeira, apesar dos zoneamentos municipais a considerarem como zona urbana, identificou-se quatro situações que apesar de apresentarem origem comum devem ser abordadas de maneira diferente em função da fase de ocupação em que se encontram: loteamentos que tornaram-se áreas urbanas consolidadas, loteamentos implantados mas com baixo adensamento, loteamentos não implantados e terrenos não loteados.

A preocupação ambiental com a conservação das restingas litorâneas está sendo negligenciada nas políticas públicas municipais, traduzidas pelos alvarás de construção em áreas protegidas por lei, falta de fiscalização ambiental e ausência de estratégias de conservação. A reversão desse processo vem sendo discutida por programas específicos, mas não priorizada nas esferas locais.

\section{Referências Bibliográficas}

ASMUS, M. L.; KITZMANN, D. I. S.; LAYDNER, C. Gestão Costeira no Brasil. Estado atual e perspectivas. Montevideo: Ecoplata, 2004. 63p.

BALNEÁRIO GAIVOTA. Balneário Gaivota Prefeitura. Disponível em: $<$ http://balneariogaivota.sc.gov.br/> Acesso em: 23 jul. 2014.

BASTOS, J.M. Considerações sobre a urbanização do litoral catarinense. In: SIMPÓSIO DE GEOGRAFIA URBANA, X., 2007, Florianópolis. Anais...: SIMPURB, 2007. p. 269-276. BERNARD, H.R. Research Methods in Anthropology: Qualitative and quantitative 
approaches. 4 ed. Oxford: AltaMira Press, 2006. 803p.

BESER DE DEUS, L.A. Espaço e tempo como subsídios à construção de cenários de uso e cobertura da terra para o planejamento ambiental na Amazônia: o caso da bacia do Rio Acre. Rio de Janeiro, 2013. 400 f. Tese (Doutorado em Planejamento Energético) - COPPE, Universidade Federal do Rio de Janeiro.

BISOL, C.A. Estratégias de pesquisa em contextos de diversidade cultural: entrevistas de listagem livre, entrevistas com informantes-chave e grupos focais. Estudos de Psicologia, Campinas, v. 29 (Supl.), p. 719-726, outubro - dezembro, 2012.

COHENCA, D. Modelagem de cenários de ocupação no litoral sul de Santa Catarina utilizando técnicas de análise geoespacial. Florianópolis, 2016. 149 f. Dissertação (Mestrado em Geografia) - Centro de Filosofia e Ciências Humanas, Universidade Federal de Santa Catarina.

COHENCA, D.; CARVALHO, R. Comparação de métodos de classificação OBIA, Máxima Verossimilhança e Distância Mínima em imagem OLI/Landsat-8 em área de alta diversidade de uso do solo. In: SIMPÓSIO BRASILEIRO DE SENSORIAMENTO REMOTO, XVII, 2015, João Pessoa. Anais..., 2015. p.1035-1042.

CORDAZZO, C.V.; SEELIGER, U. Guia Ilustrado da Vegetação Costeira do Extremo Sul do Brasil. Rio Grande: Editora da FURG, 1995. 275p.

DIEGUES, A.C. Human populations and coastal wetlands: conservation and management in Brazil. Ocean \& Coastal Management, v.42, n.2, p. 187-210, 1999.

IBGE. Contagem da População - 1996. Disponível em: <http://www. ibge.gov.br/home/estatistica/populacao/contagem/> Acesso em: 24 mar. 2015.

IBGE(a). Censo Demográfico 2000: Características da População e dos Domicílios: Resultados do universo. Disponível em: $<$ http://www.ibge. gov.br/home/estatistica/populacao/censo2000/> Acesso em: 12 nov. 2014.

IBGE(b). Censo Demográfico 2010. Disponível em: <http://www. censo2010. ibge.gov.br> Acesso em: 12 nov. 2014.

LAMBIN, E. F. et al. The causes of land-use and land-cover change: moving beyond the myths. Global environmental change, v. 11, n. 4, p. 261-269, 2001.

MMA - MINISTÉRIO DO MEIO AMBIENTE. Projeto Orla: Fundamentos para gestão integrada. Brasília, 2002. $78 \mathrm{p}$.

MORAES, A.C.R. Contribuições para a gestão da zona costeira do Brasil: elementos para uma geografia do litoral brasileiro. São Paulo: Annablume, 2007.

NUNES, I.T. A BR-101 e a migração para o litoral em Santa Catarina. Florianópolis, 2008. 79 f. Monografia (Graduação em Ciências Econômicas) - Universidade Federal de Santa Catarina.

PASSO DE TORRES. Prefeitura de Passo de Torres. Disponível em: $<$ http://www.passodetorres.sc.gov.br/> Acesso em: 23 jul. 2014.

PEREIRA, R.M.F.A. Formação sócio-espacial do litoral de Santa Catarina (Brasil): gênese e transformações recentes. Geosul, v. 18, n. 35, p. 99-129. 2003.

RICHARDSON, R.J.; PERES, J.A. Pesquisa social: Métodos e técnicas. São Paulo: Atlas, 1985.

RINDFUSS, R.R.; WALSH, S.J.; TURNER II, B.L.; FOX, J.; MISHRA, V. Developing a science of land change: challenges and methodological issues. Proceedings of the National Academy of Sciences of the United States of America, v. 101, n. 39, p. 187-210, 1999.

SANTOS, M. A natureza do espaço: técnica e tempo, razão e emoção. 4 ed. São Paulo: Edusp, 2006. 259 p.

SECRETARIA DE ESTADO DO PLANEJAMENTO. Revisão do plano de gestão da zona 
costeira setor 05 - Sul. Florianópolis: Relatório Oficial da Diretoria de Desenvolvimento das Cidades/SPG/Governo de Santa Catarina, 2013. 50 p.

SECRETARIA DE ESTADO DO PLANEJAMENTO. Roteiro metodológico de abordagem das questões que serão objeto de análise para a construção do termo de ajuste de conduta para os municípios do litoral sul de Santa Catarina. Florianópolis: Relatório Oficial da Diretoria de Desenvolvimento das Cidades/SPG/Governo de Santa Catarina, 2014. 36 p.

VELDKAMP, A.; LAMBIN, E.F. Predicting land-use change. Agriculture, Ecosystems and Environment, n. 85, p. 1-6, 2001.

VERBURG, P.H. The representation of human-environment interactions in land change research and modelling. in: MANFREDO, M.J.; VASKE, J.J.; RECHKEMMER, A.; DUKE, E.A. (eds). Understanding Society and Natural Resources: Forging new strands of integration across the social sciences. Springer Open, 2014. Cap. 8. p. 161-177.

VERBURG, P. H., SCHOT, P. P., DIJST, M. J., \& VELDKAMP, A. Land use change modelling: current practice and research priorities. GeoJournal, v. 61, n. 4, p. 309-324, 2004.

Recebido em julho de 2016.

Aceito em dezembro de 2016. 